\title{
Solitary fibrous tumor surrounding the carotid sheath
}

\author{
Guillermo Gómez-Oliveira ${ }^{1}$, Modesto Álvarez-Flores ${ }^{1}$, Ignacio Arribas-García ${ }^{1}$, Carlos Martínez-Gimeno ${ }^{1}$
}

Hospital Universitario de Canarias, Servicio de Cirugía Oral y Maxilofacial. La Laguna. Santa Cruz de Tenerife

Correspondence:

Hospital Universitario de Canarias,

Servicio de Cirugía Oral y Maxilofacial,

Ofra s/n. La Cuesta,

38320 La Laguna.

Santa Cruz de Tenerife, Spain,

ggomoli@hotmail.com

Received: 10/01/2009

Accepted: 30/07/2009

\author{
Gómez-Oliveira G, Alvarez-Flores M, Arribas-García I, Martínez-Gime- \\ no C. Solitary fibrous tumor surrounding the carotid sheath. Med Oral \\ Patol Oral Cir Bucal. 2010 Mar 1;15 (2):e395-7. \\ http://www.medicinaoral.com/medoralfree01/v15i2/medoralv15i2p395.pdf

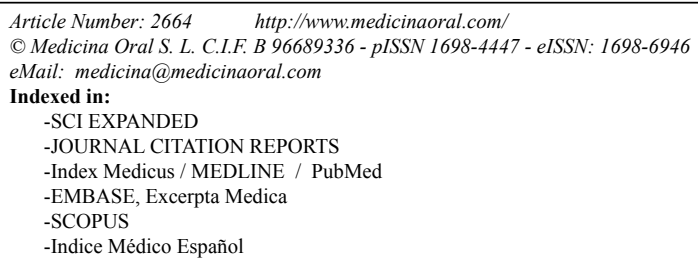

\begin{abstract}
Solitary fibrous tumors (SFTs) are rare spindle cell neoplasms that are mostly found arising from the pleura. Although SFTs recently have been reported in other regions, they are rare in the head and neck and have often been misdiagnosed due to their rarity. SFTs are benign in most cases. Clinically, SFTs usually manifest as wellcircumscribed, slow-growing, smooth and painless masses. Symptoms are often minimal, although they may include sore throat, difficulty in swallowing, change of voice or trismus. CT-Scan and MRI are the most sensitive imaging procedures used. The treatment of choice is complete surgical excision of the lesion. Because recurrences have been noted up to 30 years after surgery, long-term follow up is mandatory. In this article, we present a case of a Solitary Fibrous Tumor arising in the parapharyngeal space in a 20 -year-old man, involving the carotid sheath, treated by surgical excision with no recurrence after 1 year. The clinical presentation, surgical management and pathological findings are described.
\end{abstract}

Key words: Solitary fibrous tumor, parapharyngeal space, surgical excision, follow-up.

\section{Introduction}

SFTs are rare spindle cell neoplasms that are mostly found arising from the pleura. First described by Klemperer and Rabin in 1931 (1-3). Extraserosal SFTs in the head and neck are rare and even more in the parapharyngeal space $(1,2)$.

SFTs are benign in most cases, but 10 to $15 \%$ of extrapleural tumors show malignant behavior (2).

SFTs usually present as slow-growing and painless masses $(2,3)$. Symptoms are often minimal although may be present such as sore throat, difficulty in swallowing, change of voice or trismus (2).

Diagnosis is based on radiological findings. CT-scan and MRI are the most frequently procedures used (1). The differential diagnosis includes peripheral nerve tumors, hemangioperycitomas, salivary gland tumors, lymphomas, lipomas or paragangliomas (2).

Surgical excision is the treatment of choice. As recurrences have been reported, even 30 years after surgery, a long-term follow up is recommended (2).

\section{Case Report}

A 20-year-old man visited our Department referred from another Surgery Department with a biopsy-proven a solitary fibrous tumor in the neck. Physical examination revealed a large and asymptomatic cervical mass in the left upper neck. Computed tomography (CT) showed a heterogeneously enhanced large mass in the parapharyngeal space extending from submandibular gland to 
the thyroid cartilage, involving carotid artery and displacing laterally the internal jugular vein measuring 50 x $30 \mathrm{~mm}$. Magnetic resonance imaging (MRI) showed this lesion to be clearly circumscribed with a lobulated contour (Fig. 1). There was no invasion of the surroun-

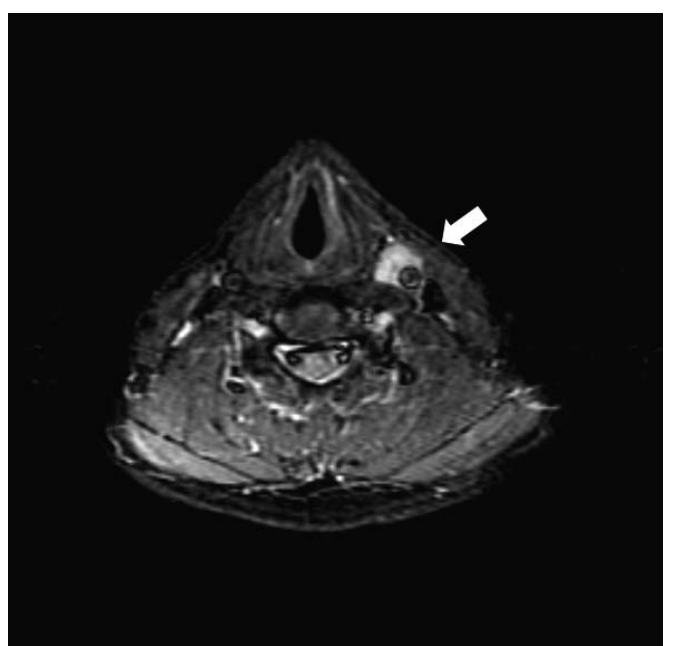

Fig. 1. MRI showing the tumor surrounding the carotid artery (white arrow).

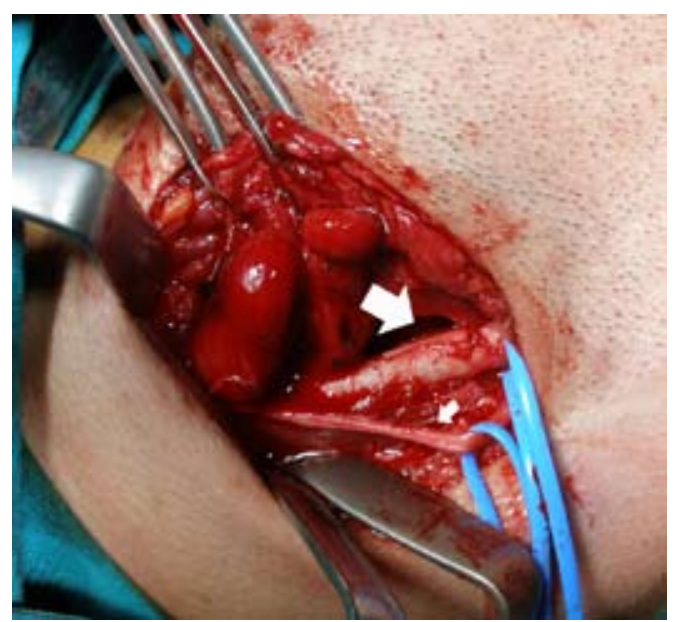

Fig. 2. Intraoperative aspect. It shows the carotid artery (big arrow) and the vagus nerve (small arrow) just being separated from the tumor.

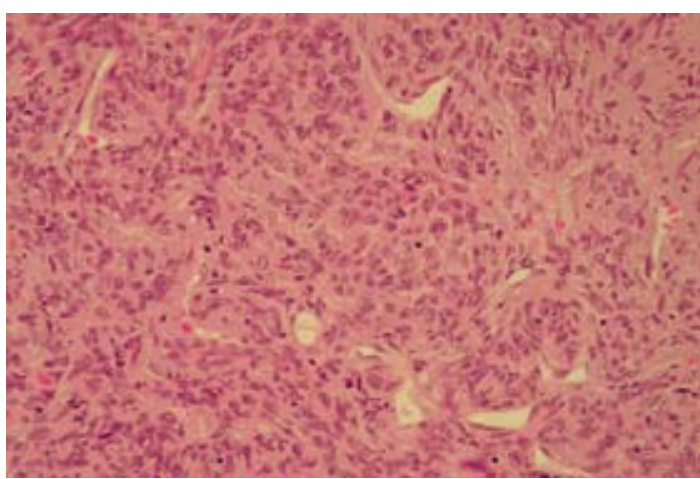

Fig. 3. Microscopic aspect of the tumor (HE x 200). ding soft tissues. An angio - MRI scan was performed in order to check the permeability of the vascular cervical and cerebral axis. It showed no obstruction of the carotid artery nor the internal jugular vein as well as a permeable Willis polygone.

A transcervical approach was used for the resection under loupe magnification. The spinal accessory nerve and carotid artery were conserved in spite of being involved in the tumor (Fig. 2). Macroscopic examination showed the tumor to be lobulated with a smooth surface measuring $50 \times 35 \times 20 \mathrm{~mm}$. Histopathological examination demonstrated prominent vascularity with "hemangiopericytomatous pattern." The tumor was mainly composed of spindle cells with varying amounts of collagen known as "patternless pattern" (Fig. 3). Immunohistochemically, the tumor tissues were strongly positive for CD34, CD99, bcl-2 and vimentin but negative for S-100 protein. The Ki-67 proliferative index was low.

On the basis of these findings, the tumor was diagnosed as solitary fibrous tumor. In the postoperative course a recurrent laryngeal nerve paralysis was observed but successfully disappeared within 3 months. The patient has been followed up for 12 months with no evidence of recurrent disease.

\section{Discussion}

Solitary fibrous tumors (SFTs) were first described by Klemperer and Rabin in 1931. SFTs are rare spindle cell neoplasms that are mostly found arising from the pleura. Extraserosal SFTs have been increasingly reported in recent years, although in the head and neck are rare (1-4). The most common sites reported in the head and neck are the oral cavity, sinonasal tract and the orbit. Only less than five previous cases have been reported in the parapharyngeal space $(5,6)$.

The tumors mainly occur in middle-aged or elderly patients between the fourth and eighth or third to sixth decades of life depending on the authors, without clear gender predominance. They seem to be originated from cells of fibroblastic or myofibroblastic lineage $(2,5)$.

SFTs are benign in most cases, but 10 to $15 \%$ of extrapleural tumors show malignant behavior in the form of recurrent or metastatic disease in the lungs, liver and bone (2).

Clinically, SFTs usually present as well-circumscribed, slow-growing, smooth and painless masses with a consistency that ranges from soft to dense. The slow progression of symptoms allowed these masses to grow to massive size upon presentation reaching a large size of more than $10 \mathrm{~cm}$, sometimes resulting in compression syndromes $(2,5)$.

Symptoms are often minimal although may be present such as sore throat, difficulty in swallowing, change of voice or trismus (2).

Most cases are diagnosed through an incidental radio- 
logic finding or as a result of symptoms related to a mass effect (2). CT-Scan and MRI are the most sensitive imaging procedures used (7-9).

The heterogeneous aspect on MRI correlates to the presence of dense fibrous tissue within the tumor, that are less likely to enhance postcontrast, alternating with vascularity areas that strongly enhances with it. These findings are consistent with previous experiences reported in the literature (8).

Microscopic features ranges from those of predominantly fibrous lesions composed of round-to-spindle cells in a collagenous background to those of more cellular and less fibrous neoplasms $(2,10,11)$.

The well-circumscribed microscopic fashion justifies the abscense of radiological surrounding soft tissue infiltration, accordingly with authors like Jeong et al. (12).

Inmunohistochemically, the tumours express CD34 and CD99. Bcl-2, EMA, SMA, vimentin and factor XIIIa may occasionally be expressed. They are usually negative for desmin, cytokeratin, muscle, vascular and neural markers such as S-100 protein and HMB-45 $(1,10)$.

The differential diagnosis includes peripheral nerve sheath tumors, angioleiomyomas, solitary miofibromas, hemangioperycitomas, salivary gland tumors, lymphomas, lipomas or paragangliomas (2).

The treatment of choice is complete surgical excision of the lesion $(1,2)$. Because these tumors display strong vascularization, the possibility of profuse bleeding during resection must be considered (2).

Resectability is the most important indicator of clinical outcome (13). So, if the initial excision is microscopically benign, no further treatment is recommended (6). Nevertheless, as a result of the tumor's rarity and the limited experience with SFTs, the effectiveness of adjuvant treatment options in malignant cases or positive surgical margins after resection cannot yet be defined $(1,2)$ although Ganly et al. (8) stated that patients with positive surgical margins or whose tumors have a malignant component benefit from adjuvant postoperative radiation therapy.

Although SFTs are reportedly nonmalignant, it is estimated that up to $10 \%$ of extrapleural SFTs were associated with local recurrence or histologic malignancy $(1,5)$.

Because recurrences have been noted up to 30 years after surgery, long-term follow up is mandatory for all patients, even in microscopically benign tumors (2).

\section{References}

1. Hashimoto D, Inoue H, Ohbayashi C, Nibu K. Solitary fibrous tumor in the parapharyngeal space. Otolaryngol Head Neck Surg. 2006;134:535-6

2. Ridder GJ, Kayser G, Teszler CB, Pfeiffer J. Solitary fibrous tumors in the head and neck: new insights and implications for diagnosis and treatment. Ann Otol Rhinol Laryngol. 2007;116:265-70.

3. England DM, Hochholzer L, McCarthy MJ. Localized benign and malignant fibrous tumors of the pleura. A clinicopathologic review of 223 cases. Am J Surg Pathol. 1989;13:640-58.

4. Witkin GB, Rosai J. Solitary fibrous tumor of the upper respiratory tract. A report of six cases. Am J Surg Pathol. 1991;15:842-8.

5. El-Sayed IH, Eisele DW, Yang TL, Iezza G. Solitary fibrous tumor of the retropharynx causing obstructive sleep apnea. Am J Otolaryngol. 2006;27:259-62.

6. Suárez Roa Mde L, Ruíz Godoy Rivera LM, Meneses García A, Granados-García M, Mosqueda Taylor A. Solitary fibrous tumor of the parotid region. Report of a case and review of the literature. Med Oral. 2004;9:82-8.

7. Kim HJ, Lee HK, Seo JJ, Kim HJ, Shin JH, Jeong AK, et al. MR imaging of solitary fibrous tumors in the head and neck. Korean J Radiol. 2005;6:136-42.

8. Ganly I, Patel SG, Stambuk HE, Coleman M, Ghossein R, Carlson D, et al. Solitary fibrous tumors of the head and neck: a clinicopathologic and radiologic review. Arch Otolaryngol Head Neck Surg. 2006;132:517-25.

9. Wakisaka N, Kondo S, Murono S, Minato H, Furukawa M, Yoshizaki T. A solitary fibrous tumor arising in the parapharyngeal space, with MRI and FDG-PET findings. Auris Nasus Larynx. 2009;36:367-71.

10. Ali SZ, Hoon V, Hoda S, Heelan R, Zakowski MF. Solitary fibrous tumor. A cytologic-histologic study with clinical, radiologic, and immunohistochemical correlations. Cancer. 1997;81:116-21.

11. Gold JS, Antonescu CR, Hajdu C, Ferrone CR, Hussain M, Lewis JJ, et al. Clinicopathologic correlates of solitary fibrous tumors. Cancer. 2002;94:1057-68.

12. Jeong AK, Lee HK, Kim SY, Cho KJ. Solitary fibrous tumor of the parapharyngeal space: MR imaging findings. AJNR Am J Neuroradiol. 2002;23:473-5.

13. Vo QT, Wolf JA, Turner JW, Murkis M, Saw D, Shemen LJ. Solitary fibrous tumor of the parapharyngeal space. Ear Nose Throat J. 2007;86:502-5. 